\title{
Um jogo sério aplicado à saúde com foco em epidemiologia: Apoena
}

\author{
Barbara Adriana P. Barata1, Felipe C. Couto ${ }^{2}$, Danielle C. C. Couto ${ }^{1}$ \\ ${ }^{1}$ Laboratório Interdisciplinar em Tecnologias, Educação e Computação - Universidade \\ Federal do Pará (UFPA) - Campus Ananindeua, PA - Brasil \\ ${ }^{2}$ Bacharelado em Sistemas de Informação - Faculdade de Estudos Avançados do Pará \\ (FEAPA), Belém, PA- Brasil \\ \{barbarapires249, felipe.carrara.couto\}@gmail.com, danifceufpa.br
}

\begin{abstract}
This paper presents a prototype of a mobile application based on an epidemiological system, using an educational game to promote voluntary participation and disseminate environmental awareness in the fight against Dengue in public schools in Ananindeua. The Apoena Game is based on the agile methodology and uses the Construct 2 platform. The post-production game offers mechanisms for decision-making and spatialization of data obtained from real-life Dengue focuses, helping the discussion in schools on environmental awareness and health problems stemming from lack of basic sanitation.
\end{abstract}

Resumo. Este artigo apresenta um protótipo de uma aplicação móvel baseada em sistema epidemiológico, utilizando um jogo educativo para promover participação voluntária e disseminar a conscientização ambiental no combate à Dengue em escolas públicas de Ananindeua. O Jogo Apoena tem suas bases na metodologia ágil e utiliza a plataforma Construct 2. O jogo está em fase de pós-produção oferece mecanismos para tomadas de decisões e a espacialização de dados obtidos de focos de Dengue da vida real, auxiliando a discussão em escolas sobre a consciência ambiental e problemas de saúde derivados da falta de saneamento básico.

\section{Introdução}

De acordo com Argolo et al. (2008) as Geotecnologias são ferramentas que auxiliam os processos de mapeamento de doenças; considerando que o Geoprocessamento em conjunto com os Sistemas de Informações Geográficas (SIG) apoiam Sistemas Epidemiológicos e são instrumentos de aperfeiçoamento da saúde auxiliando no planejamento, prestação e na avaliação dos serviços à população.

Este trabalho teve como objetivo principal desenvolver um protótipo de uma aplicação móvel baseada em sistemas epidemiológicos, a fim de proporcionar compreensão do controle da doença dengue, utilizando um jogo sério como mecanismo para suscitar a conscientização ambiental em crianças de escolas públicas no município de Ananindeua, desta maneira tornando a população uma colaboradora na proteção e melhorias do meio ambiente.

O presente artigo segue com a seção 2 apresentando sobre os procedimentos metodológicos que descreve a produção da aplicação móvel do jogo Apoena, a seção 3 
VIII Congresso Brasileiro de Informática na Educação (CBIE 2019)

Anais dos Workshops do VIII Congresso Brasileiro de Informática na Educação (WCBIE 2019)

exibe os resultados preliminares do desenvolvimento do jogo e pôr fim a seção 4 mostra as considerações finais.

\section{Métodos}

A metodologia segue três etapas (Figura 1) adaptada de Schuytema (2008) apud Sobrinho et al. (2015) que são: 1) Pré-produção - fase de conceituar, escolher as ideias, criar o roteiro e elaborar o Short Game Design Document for Digital Educational Games (SGDDEdu); 2) Produção - designer do ambiente e seus personagens, escrita do códigofonte e a integração com o Google Maps; e 3) Pós-produção - suporte ao jogo e também a fase de ajuste aos testes internos e aplicações com os usuários externos.

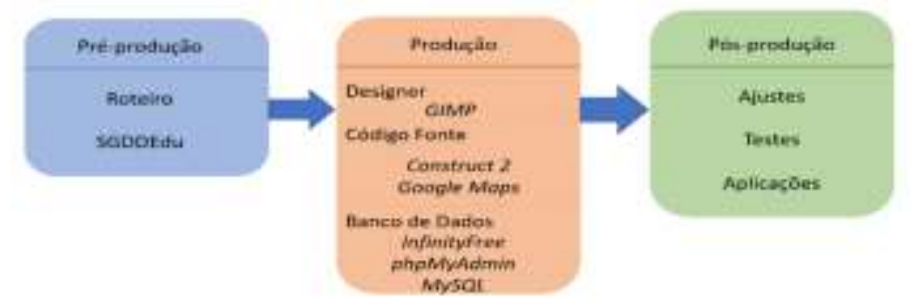

Figura 1: Estrutura das etapas de elaboração do Jogo Apoena.

\subsection{Roteiro do jogo Apoena}

O jogo apresenta 4 missões para capturar uma determinada quantidade de mosquitos. A lógica do jogo é composta por: menu do usuário; cadastro do foco de dengue; e ambiente do jogo. Um critério para incentivar mais o entretenimento é a distribuição de bônus de velocidade e remédios para o personagem principal ao longo das missões. Os bônus estão relacionados ao cadastro de focos de dengue tendo como base as coordenadas geográficas do ambiente que o jogador se encontra, sendo necessário anexar uma foto do foco identificado.

O estágio da primeira missão é o registro do primeiro foco de dengue a partir do qual o jogador receberá um bônus de velocidade para a caçadora, chamada de Mani. As 3 missões seguintes são aventuras de Mani caçando mosquitos em 2 ambientes que tem metas pré-estabelecidas de quantidade de mosquitos a serem capturados (20, 30 e 40). Os bônus estarão localizados aleatoriamente nas missões e o jogador encontrará obstáculos ao se deparar com objetos relacionados a doença o qual poderão deixar Mani doente e/ou perder uma vida se não encontrar o bônus de remédio a tempo.

Na primeira versão o jogo é composto por dois personagens, a caçadora Mani que inicia com 3 vidas ao longo das missões e o mosquito da dengue que é multiplicado nas missões. O jogo Apoena tem em sua $1^{a}$ fase apenas um cenário para as missões, o qual é composto por uma área urbana com fatores habituais: céu, casas ou prédios. Foram anexados blocos para os movimentos da personagem Mani.

\subsection{Etapas de desenvolvimento do Jogo Apoena}

Na pré-produção foi confeccionado o roteiro que direcionou as primeiras ideias sobre o jogo Apoena e foi elaborado o SGDDEdu o qual segundo Martins et al. (2019) é uma ferramenta textual curta de descrição do jogo adaptada com uma lista de objetivos pedagógicos vinculados a BNCC (Base Nacional Comum Curricular).

Durante a etapa de produção ocorreu a modelagem do ambiente (personagens e cenário), seguido pela elaboração do banco de dados via web e do código-fonte que foi 
dividida em duas etapas: (1) pesquisa e estudo da linguagem, ferramentas e APIs de programação mobile; e (2) construção do protótipo utilizando metodologia ágil.

As ferramentas selecionadas foram a plataforma Construct 2 o qual é um criador de jogos HTML5 projetado especificamente para jogos em 2D; o GIMP (GNU Image Manipulation Program) versão 2.10.12 o qual é um software livre para a edição de imagens; PhpMyAdmin 5.6, utilizado para administrar o MySQL hospedado por meio do Infinityfree e o Google Maps que dá suporte ao georreferenciamento dos dados de foco do jogo utilizando os plugins da plataforma.

No ambiente Construct 2 foram implementadas as telas que fazem comunicação com o banco de dados: cadastro do usuário e login; cadastro do foco de dengue com suporte do Google Maps gerando a localização em tempo real, utilizando o plugin Geolocation e nesta mesma tela há a opção de upload para adicionar uma foto de um foco de dengue e a tela da caça aos mosquitos que contém informações sobre o ranking de melhores jogadores.

A principal dinâmica de movimento do jogo foi aplicada no cenário composto por blocos e plataformas, ativada com auxílio da função bullet na área set angle of motion (ângulo de movimento). Mani tem como funções programadas as ações de correr e pular, enquanto o mosquito por sua vez é encontrado em série no decorrer do cenário.

A pós-produção foi direcionada aos testes internos que ajustaram erros de programação para geração do primeiro protótipo apto a ser utilizado pelas escolas públicas de Ananindeua a partir de agosto de 2019, desta forma obteremos resultados por meio da participação voluntária dos alunos, possibilitando a análise dos dados georreferenciados do Jogo Apoena, ajustando o protótipo a uma versão beta que será disponibilizada no Google Play Store até dezembro de 2019.

\section{Resultados e Discussão}

O primeiro nível contém as seguintes telas do jogo: a) Tela Inicial; b) Menu do Usuário; e c) Cadastro do Foco de dengue. A tela de cadastro do foco de dengue (Figura 2) é formada por botões para estabelecer as ações de coletas dos focos a partir da localização em tempo real, permitindo determinar as coordenadas relativas ao mundo real do jogador.

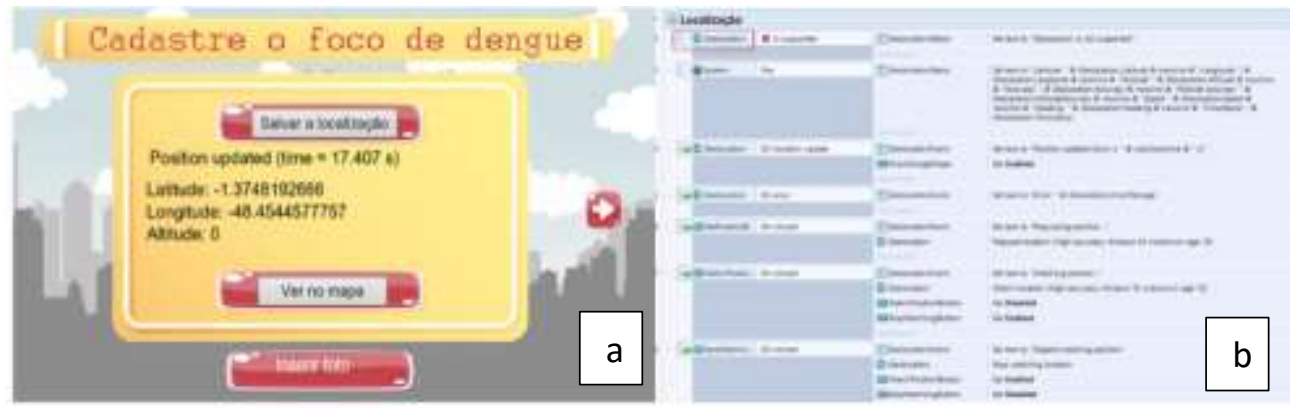

Figura 2: Cadastro do foco de Dengue(a); Aplicação do plugin Geolocation (b)

A estrutura do jogo (Figura 3) passou por testes, a partir da ferramenta "Run Layout", por meio do qual foi possível a construção da mecânica do primeiro nível do jogo e realizou-se as análises de correções de erros de programação. 


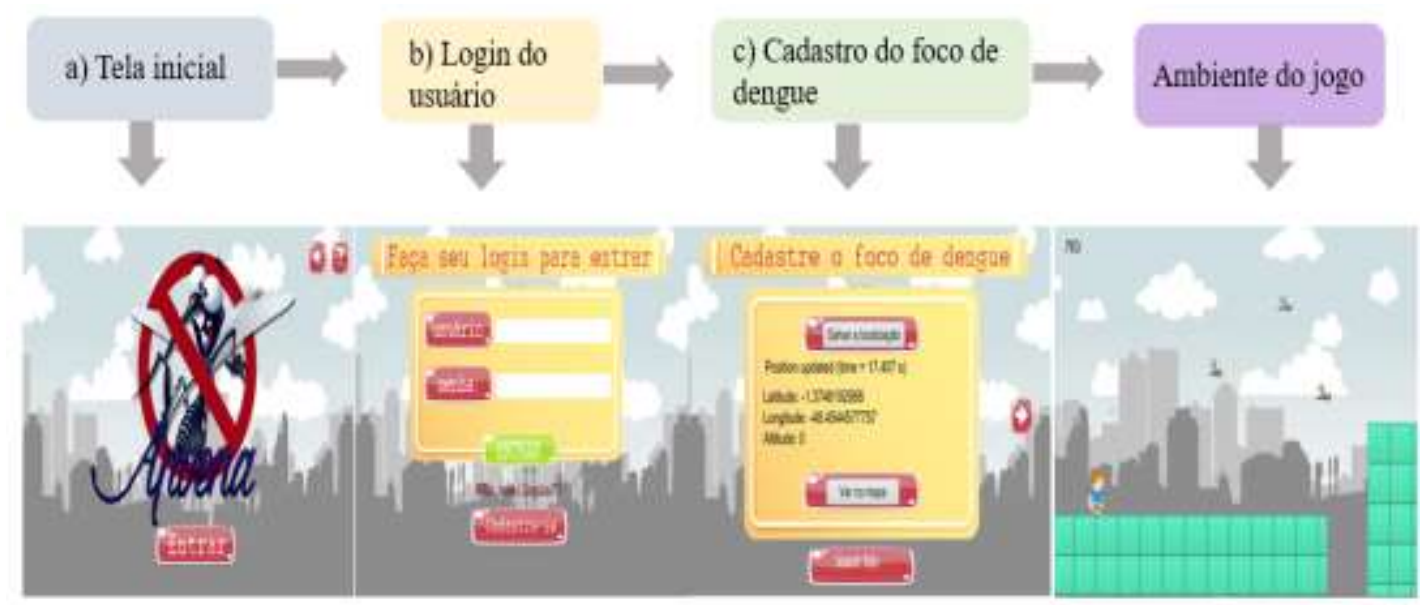

Figura 3. Estrutura das telas do Jogo Apoena.

Nos primeiros testes constatamos erros de movimentação do cenário e erros nos blocos que surgiam de forma randômica na cena. A função bullet (função de movimento) foi necessária para o desempenho da dinâmica dos personagens e suas interações, entre elas, colisões entre a personagem Mani e os mosquitos, além dos obstáculos que surgem no decorrer das telas do jogo.

\section{Considerações Finais}

As pessoas são expostas a diversas situações e riscos os quais podem afetar sua saúde, então a criação de mecanismos digitais é bem relevante para a prevenção de epidemias, principalmente em territórios suscetíveis a moléstias, como a Dengue, por exemplo. $\mathrm{O}$ jogo Apoena promove participação voluntária de estudantes do município de Ananindeua - PA, como ferramenta de colaboração a saúde coletiva, de maneira a contribuir com o ensino de conceitos epidemiológicos em escolas públicas, coletando dados reais para avaliar a frequência dos focos de dengue próximo as escolas.

O Jogo Apoena passará por testes em 3 escolas públicas de Ananindeua com alunos de turmas de $4^{\circ}$ e $9^{\mathrm{a}}$ ano do ensino fundamental. Ao final do ano de 2019 a versão beta do jogo Apoena será disponibilizada para os sistemas operacionais Android e iOS na plataforma Google Play Store, possibilitando que outras escolas também utilizem este aplicativo gratuitamente.

\section{Referências}

Argolo, A. M.; Felix, M.; Pacheco, R.; Costa, J. (2008). Doença de chagas e seus Principais Vetores no Brasil: Fundação Oswaldo Cruz. Rio de Janeiro.

Martins, R. S.; Raulino, F.; Burlamaqui, A.; \& Burlamaqui, A. (2019). SGDDEdu: A Model of Short Game Design Document for Digital Educational Games. International Journal for Innovation Education and Research, 7(2), 167-180.

Sobrinho, F. A., Silva, U. V., Ferreira, L. N., Andrade, A. M., Neto, C. P., Rodrigues, A., \& Couto D. C. C. (2015). Jogo do Boto: Serious Game para Sensibilização Ambiental de estudantes da Região Amazônica. In: SBC - Proceedings of SBGames, TeresinaPI: Artigos, p. 836- 845. 